\title{
Applying the U.S. Model of Social Work Education Curriculum to Libyan Education
}

By Zeinab Abulhul

Widener University

Abstract- The Libyan government urgently needs a professional social workers' mission to help decrease social problems that have emerged and been aggravated due to civil war and political conflicts. However, the present social work community in Libya cannot mitigate social problems or simplify social services effectively to meet people's needs. Thus, teaching and learning methodologies need to be developed inside and outside educational institutions so that the challenges presently facing Libyan society can be overcome. The purpose of this paper is to suggest adopting an American social work curriculum experience in Libyan social work education according to Libyan ideology. The researcher depicts nine social work competencies (e.g., knowledge, professional values, skills, and professional processes and practices), as well as a set of behaviors that reflect social workers' competencies that relate to the social work curriculum applied in colleges in the United States. The author's goal is to encourage Libyan social work professionals to take advantage of this knowledge and these experiences to develop the Libyan social work education curriculum. This could ensure that graduates of social work programs are qualified to help people deal with social problems when they enter the workforce.

Keywords: libya, government, mission, ideology, american, social work, curriculum, education, teaching.

GJHSS-G Classification: FOR Code: 339999p

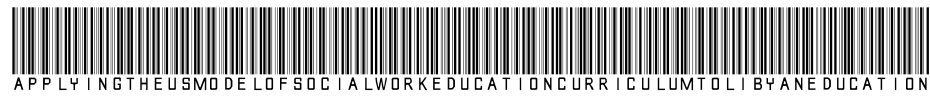

Strictly as per the compliance and regulations of:

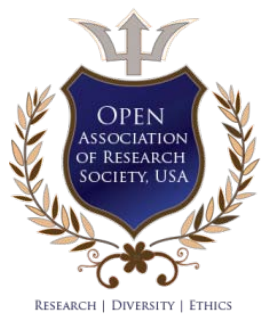

(C) 2021. Zeinab Abulhul. This is a research/review paper, distributed under the terms of the Creative Commons AttributionNoncommercial 3.0 Unported License http://creativecommons.org/licenses/by-nc/3.0/), permitting all non-commercial use, distribution, and reproduction in any medium, provided the original work is properly cited. 


\title{
Applying the U.S. Model of Social Work Education Curriculum to Libyan Education
}

\author{
Zeinab Abulhul
}

\begin{abstract}
The Libyan government urgently needs a professional social workers' mission to help decrease social problems that have emerged and been aggravated due to civil war and political conflicts. However, the present social work community in Libya cannot mitigate social problems or simplify social services effectively to meet people's needs. Thus, teaching and learning methodologies need to be developed inside and outside educational institutions so that the challenges presently facing Libyan society can be overcome. The purpose of this paper is to suggest adopting an American social work curriculum experience in Libyan social work education according to Libyan ideology. The researcher depicts nine social work competencies (e.g., knowledge, professional values, skills, and professional processes and practices), as well as a set of behaviors that reflect social workers' competencies that relate to the social work curriculum applied in colleges in the United States. The author's goal is to encourage Libyan social work professionals to take advantage of this knowledge and these experiences to develop the Libyan social work education curriculum. This could ensure that graduates of social work programs are qualified to help people deal with social problems when they enter the workforce.
\end{abstract}

Keywords: libya, government, mission, ideology, american, social work, curriculum, education, teaching.

\section{InTRODUCTION}

C ontinuous developments in technology have made daily life more complicated, and have consequently affected perceptions of countries' political, social, and economic conditions. In addition to changing our understanding of social problems and ways of addressing them, constant technology development requires a change in the way social work is taught and learned, so that the social work profession stays linked to social and educational institutions (Serogi, 2012). This linkage could not be successful without changing our teaching and learning methodologies inside and outside of educational institutions (Serogi, 2012).

Many social work professionals in developing countries believe it is important to look to developed countries for ways of improving teaching and learning methods, and educational curricula (Pawar, 2014; United Nations Educational, Scientific and Cultural Organization [UNESCO], 1999). They consider that development is the backbone of upgrading the social

Author: Department of Center for Social Work Education, School of Health and Human Services, Widener University, Chester, PA, USA. Department of Social Work, University of Tripoli, Tripoli, Libya. e-mail: zaino.abulhul@gmail.com work profession and social workers' professional performance to keep up with contemporary social issues resulting from changes in social, economic, and political contemporary circumstances (Pawar, 2014; United Nations Educational, Scientific and Cultural Organization [UNESCO], 1999).

Many developing countries have acknowledged there is an essential need to improve social work education. For instance, in Saudi Arabia, a survey on social work education (Albrithen, 2014) revealed that social work professionals acknowledged there were some negative aspects of current social work education that required curriculum reform and improvements in education processes. They also acknowledged scientific standards need to be developed to assess the social work education curriculum. (Albrithen, 2014). Another a study on developing social work education, conducted in Egypt, showed there was a need to modernize social work education and educators to address contemporary social issues by creating a model that can evaluate the Egyptian social work education curriculum (Soliman \& Abd Elmegied, 2010).

Developing countries that have changed their political paths, such as Libya, are now working to upgrade their social work curriculum (Libyan Cloud News Agency, 2018). It is important these countries understand that producing high numbers of social workers without adequately educating them to changing social conditions would burden the state budget, which would create detraction from the need to have qualified social workers in public social institutions. Therefore, to be successful in producing qualified social workers who can address contemporary challenges, contribute to social changes, and influence decision-makers to consider their recommendations, Libyans should be open to learning from other cultures and taking advantage of more advanced countries' experiences with social work education.

The United States has successfully connected and integrated the social work profession with its social and educational institutions (Council on Social Work Education [CSWE], 2015). This success resulted from continuous assessment and development of the social work education curriculum, with a focus on maintaining social workers' competencies and training social workers to face global challenges (CSWE, 2015).

In this paper, I describe my proposal for Libya to take advantage of the United States' knowledge and 
experience in developing a social work education curriculum. By developing social work education, Libya can encourage social work professionals to apply this knowledge and experience to improve social work education. Other developing countries have successfully applied the U.S. social work education model in developing their social work education curriculum, such as India, Philippines, Indonesia, and Singapore (Brigham, 1982). This proposal refers to the CSWE 2015 Education Policy and Accreditation Standards for baccalaureate and master's social work programs in the United States to inform Libyan social work curriculum development. Using the American model can help upgrade Libyan social work education curriculum to be consistent with Libyan ideology.

\section{Social Work Educational Competencies}

The primary objective underlying the CSWE's (2015) policy of developing a consistent social work education curriculum in the United States is the belief that the social work profession can achieve positive changes in human rights locally and internationally. This belief is based on the profession's philosophy and work as a defender of people's rights, with a focus on limiting poverty and suffering, and on providing opportunities to help people live decent lives (CSWE, 2015). That mission can be achieved by providing education based on competencies associated with qualified social workers. These competencies include dimensions such as knowledge, professional values, skills, and professional processes and practice, as well as a set of behaviors that reflect social workers' competency (CSWE, 2015).

According to the CSWE (2015, p. 8), there are nine social work competencies related to a social work curriculum:

1. Demonstrate ethical and professional behavior.

2. Engage diversity and difference in practice.

3. Advance human rights and social, economic, and environmental justice.

4. Engage in practice-informed research and researchinformed practice.

5. Engage in policy practice.

6. Engage with individuals, families, groups, organizations, and communities.

7. Assess individuals, families, groups, organizations, and communities.

8. Intervene with individuals, families, groups, organizations, and communities, and

9. Evaluate practice with individuals, families, groups, organizations, and communities.

Next, I will review these nine competencies, and describe how each competency can be applied to Libyan social work education.

\section{a) Competency 1: Demonstrate Ethical and} Professional Behavior

In the United States, social workers are equipped with knowledge about social work practice. This knowledge includes history, philosophy, roles, responsibilities, and missions of the social work profession. Moreover, social workers believe in the principles and values of their profession, as described in the Code of Ethics of the National Association of Social Workers ([NASW], 2017). Social workers can distinguish between individual values and professional values in practice situations, when working with individuals, groups, families, and social organizations in the community. They are committed to upholding their ethical code when conducting research and issuing findings. Social workers also know that assessing their interactions with others is important for maintaining competent performance; they are aware that personal experiences can impact social work behavior and professional judgment. Social workers know that there is no limit to learning, so they consistently acquire updated information that helps them develop their skills and professional performance (CSWE 2015).

In this respect, the principles of ethical and professional behavior in the U.S. social work profession can be applied to Libyan social work education. These principles are contained in the NASW Code of Ethics, which focuses on preserving people's dignity and their right to live decent lives. This principle of ethics and professional behavior is consistent with Libyan ideology; Libyan education is grounded in the Islamic religion, even though some Libyan educators consider these ethics to be personal obligations (Abdulsalam, 2010). Thus, Libyan social workers are not penalized if they do not adhere to professional ethics. My perspective is that the NASW's ethical code is important for the Libyan social work profession and should be integrated into Libyan education. The NASW ethical code is continually being reassessed to ensure it is valid and relevant to contemporary challenges faced by social workers. Also, the Code of Ethics is concerned with social workers' competencies to ensure high quality practice. Libyan social work educators should work earnestly and urgently to adopt the NASW ethical constitution to use as a regulatory pathway for evaluating social worker competency. In 2008, Libyan social workers began their attempt to draft an Arabic social work ethical constitution based on the ethical codes used in the United States, the United Kingdom, Canada, and Australia (Al-Barithin, 2010). In this paper, I make a case for Libyan educators to complete and apply this code to the social work profession in Libya.

\section{b) Competency 2: Engage Diversity and Difference in Practice.}

This competency focuses on social work professionals being educated about the effects of 
diversity among people and recognizing that all people are not exposed to the same life events. In other words, individuals have different lives and different experiences. These experiences, both positive and negative, include injustice, poverty, marginalization, isolation, and individual power or social privilege. Social workers also are aware of diverse characteristics, such as "age, class, color, culture, gender identity and expression, immigration status, marital status, political ideology, race, religion, spirituality, sex, sexual orientation, and sovereign tribal status" (CSWE 2015, p. 7). Competent social workers also understand the impact of cultural, social, economic and political conditions on individuals, and how these conditions influence individuals' lives and behaviors and shape their identities. This knowledge makes social workers able to effectively defend people's rights (CSWE, 2015).

Engaging diversity and difference in practice is essential to developing a Libyan social work curriculum, with the exception of some areas that conflict with religious principles. For example, homosexuality and transgenderism are not accepted in Libya's general social system. Even with these exceptions, because this competency requires accommodating all people, regardless their differences, and working with and for them, using this competency will help move Libya in the direction engaging diversity in practice. Thus, this competency will upgrade social work performance in Libya. Libyan professionals should apply the U.S. model in social work education, which condemns discrimination based on race, sex, age, social class, nationality, color, political belief, personal opinion, and level of ability or mental disability. Furthermore, social workers should be prohibited from engaging in professional fraud, deception, or lies.

Professional and personal difficulties or problems, such as psychological difficulties, legal problems, addiction, and difficulties with mental problems, which could affect service provision and professional conduct, threaten the interests of clients should not be allowed to affect social workers' judgments and professional manner (Abou El Nasr, 2008).

c) Competency 3: Advance Human Rights and Social, Economic, and Environmental Justice

This competency emphasizes that social work professionals should understand the role of global interdependence, are aware of the theories of human needs and social equality and know strategies to boost social and economic equality and human rights. Also, this competency demonstrates that social workers are well-educated about human rights issues and are knowledgeable about international efforts calling for social justice for the whole of humanity (CSWE, 2015).

Professional preparation helps social workers to absorb the essential information about human rights. It also helps them to better comprehend people's issues, and help marginalized populations obtain their legal rights, such as "freedom, safety, privacy, an adequate standard of living, healthcare, and education" (CSWE, 2015 , p. 7). That understanding helps social workers advocate for vulnerable people. by influencing decisionmakers to make positive changes, and to consider people's social and economic issues when they make social, economic, and political policies (CSWE, 2015).

In my experience, Libyan social work emphasizes meeting people's basic needs socially and economically, but their practice does not include political rights. Libyan social workers in the Qaddafi regime understood that the nature of the political government did not tolerate opponents; however, they were working with individuals, groups, and communities to defend people's rights according to state policy, which made them more knowledgeable about using their professional skills to influence decision-makers to obtain social services for people in need. Since the Libyan people changed their political regime in 2011, Libyan social workers need to integrate the U.S. principles of advancing human rights and social, economic, and environmental justice into the Libyan social work curriculum. This step will expand social workers' professional potential to face social and economic issues that emerged with the new political regime, as well help social workers be open-minded about developing their practice in different social work fields (Abdul Hamid, n.d.).

\section{d) Competency 4: Engage in Practice-informed Research and Research-informed Practice}

This competency requires that social workers know various methods of inquiry and analysis in social work research. They must understand how to use quantitative and qualitative research to inform their practice. In addition, this competency demonstrates that social workers understand the rules of scientific research, and that they must be educated in dialectic thinking to answer research questions using culturally and ethically appropriate methodologies that can produce scientific social knowledge. Social workers should also understand how to connect research information to theory, and how to use a variety of resources to support the validity of their scientific social research (CSWE, 2015).

Libyan social workers use outdated information when they are enrolled in master's or doctoral programs (Dahir, 2013). According to Dahir, the influence of culture on the society makes social work students conduct research only to earn their academic degree. In order for Libya to develop a social work curriculum that is on par with international education in social work, the Libyan social work profession should adopt the U.S. standard of engaging in practice- informed research and research-informed practice. This action requires 
developing the social research curriculum of Libyan universities to keep up with education in developed countries. Using the U.S. model would help social workers conduct rigorous research in the social sciences, free from the influence of social culture (Dahir, 2013). I think that culture and society inevitably affect social sciences research. Social workers in every society, including the United States, face social and political pressure when selecting research topics and conducting research. However, being competent in research-informed practice and practice-informed research provides some guidance and protection to social work researchers, as well as educational institutions. This competency gives them a foundation for pursuing research that is in the best interests of people and communities (Houser, 2018).

\section{e) Competency 5: Engage in Policy Practice}

U.S. social work professionals know that governmental policies ensure people's rights, social equality, social welfare, and social services (CSWE, 2015). They also understand how to use local policies and resources to provide social services to people on different levels in society. Furthermore, social workers are equipped to understand the background for social policies' changes and the influence of historical, cultural and economic and global changes on social policy performance (CSWE, 2015).

The social work education curriculum in Libya includes the principle of public practice in social work, which provides the analysis of concepts contained in general practice in social work and application of general practice process in the social services and the social workers' roles in the social policy theoretically more than in practice. Taking advantage of the U.S. model would help Libyan social work professionals enrich professional practice to broaden Libyan social workers' understanding that they need to consider the implications of political changes on social workers performance with individuals, groups, and social institutions. This change could motivate Libyan social workers to critically think of ways to increase the quality of their practice, as well as the quality of all social services (Salih, 2000).

f) Competency 6: Engage with Individuals, Families, Groups, Organizations, and Communities

This competency refers to social work professionals in the United States being equipped to know the importance of human interaction among individuals and groups, and the positive impact of such communication on those entities within their social environment. Also, social workers understand how personal experiences might affect professional performance and know how to manage personal influences when working with clients. Moreover, social workers are educated to use social theories to guide their practice with individuals and community organizations (CSWE, 2015).

The social work education curriculum in Libya includes such principles as the importance of engaging social workers within different social units, such as individuals, groups, and organizational communities. Also, the Libyan social work curriculum emphasizes the importance of social workers' obligation to understand effective mechanisms that can help them improve their performance. Adopting and integrating new professional methods in the Libyan social work education curriculum would upgrade social workers' tools (e.g., technology, knowledge, and practice skills), especially when the methods are taken from advanced countries, such as the United States. Integrating these methods would help Libyan social workers improve their performance in practice, and would help social work students acquire a greater range of attitudes, skills, and knowledge. It would also help Libyan social workers gain the technical and intellectual skills that would allow them to better understand themselves and their communities (Abdu Al Aleem, n.d).

g) Competency 7: Assess Individuals, Families, Groups, Organizations, and Communities

This competency demonstrates that social workers should be able to assess individuals, families, groups, and social institutions in the community. Moreover, professional preparation can support social workers in applying human behavior theories when assessing social units, such as individuals, groups, families, social institutions, and local communities. Assessment skills can help social workers evaluate their own professional weaknesses and strengths, and how to use effective assessment processes to improve their practice performance. In addition, competent social workers know how to engage with other professionals in the assessment process, and are equipped to understand that their personal experiences might affect assessment results (CSWE, 2015).

Libyan social work professionals know the value of broadening social work students' knowledge and skills to improve their performance in professional practice. Also, they know that improving professional performance can help social workers make positive changes in the social work education field, and that integrating the U.S. model would strengthen the Libyan social work curriculum. Thus, I encourage social work professionals to consider contemporary social work education curricula and integrate modern social work concepts into the Libyan social work education curriculum. By borrowing advanced models from developed countries, and applying them according to the Libyan context, especially concepts concerning the principles of professional skills in the evaluation process, Libyan social workers would be able to provide assessments, and understand social roles and human 
relations and the influence these areas have on social situations. (Ajlani, 2005).

h) Competency 8: Intervene with Individuals, Families, Groups, Organizations, and Communities

This competency demonstrates that social workers can provide effective interventions. It emphasizes the importance of intervention processes that are grounded in social theories, which explain human behavior within the social environment. In addition, such professional preparation can help social workers understand the importance of collaborating with other professionals in the intervention process and encourage them to employ professional methods that fully consider the causes and effects of the social issues when helping individuals, groups, families find solutions to their problems (CSWE, 2015).

Developing a social work curriculum that includes competency in professional intervention skills would boost Libyan social workers' performance when critically analyzing problems and applying social theories to assist their clients (Shall, 2013).

i) Competency 9: Evaluate Practice with Individuals, Families, Groups, Organizations, and Communities

This competency emphasizes the need for social workers to be able to conduct evaluations with individuals, groups, families, and organizations, and communities. Qualified social workers know that professional evaluation increases practice performance and develops the quality of social services in social institutions, which help them meet their clients' needs. Social workers also know how to use professional evaluation by collaborating with other professionals in different disciplines, and that evaluation must be based on knowledge about social theories of human behavior in the social environment. Having quantitative and qualitative research skills would help social workers engage in evaluating social situations without bias, as well advance the effectiveness of their professional practice (CSWE, 2015).

Taking advantage of the U.S. model for teaching this competency would improve the Libyan social work education curriculum and expand social scientific knowledge in the Libyan social work literature. Social work educators know that integrating the principle of professional evaluation would enable them to apply social theories and quantitative and qualitative research to develop practice performance and improve social services. Therefore, I conclude that this competency provides a good opportunity for social work professionals to consider the advantages of improving social work education and collaborating with other countries in the social work field when studying the contemporary international social issues.

\section{ili. Social Workers' Qualities}

According to the CSWE, the nine social work education competencies should produce social workers with the following qualities:

1. Use reflection and self-regulation to manage personal values and maintain professionalism in practice situations;

2. Demonstrate professional demeanor in behavior; appearance; and oral, written, and electronic communication;

3. Use technology ethically and appropriately to facilitate practice outcomes and use supervision and consultation to guide professional judgment and behavior.

4. Apply and communicate an understanding of the importance of diversity and difference in shaping life experiences in practice at the micro, mezzo, and macro levels;

5. Present themselves as learners and engage clients and constituencies as experts of their own experiences and apply self-awareness and selfregulation to manage the influence of personal biases and values in working with diverse clients and constituencies;

6. Apply their understanding of social, economic, and environmental justice to advocate for human rights at the individual and system levels; and engage in practices that advance social, economic, and environmental justice;

7. Identify social policy at the local, state, and federal level that impacts well-being, service delivery, and access to social services;

8. Assess how social welfare and economic policies impact the delivery of and access to social services;

9. Apply critical thinking to analyze, formulate, and advocate for policies that advance human rights and social, economic, and environmental justice.

10. Apply knowledge of human behavior and the social environment, person-in- environment, and other multidisciplinary theoretical frameworks to engage with clients and constituencies;

11. Use empathy, reflection, and interpersonal skills to effectively engage diverse clients and constituencies;

12. Collect and organize data, and apply critical thinking to interpret information from clients and constituencies;

13. Apply knowledge of human behavior and the social environment, person-in- environment, and other multidisciplinary theoretical frameworks in the analysis of assessment data from clients and constituencies;

14. Develop mutually agreed-on intervention goals and objectives based on the critical assessment of strengths, needs, and challenges within clients and constituencies; and select appropriate intervention 
strategies based on the assessment, research knowledge, and values and preferences of clients and constituencies;

15. Critically choose and implement interventions to achieve practice goals and enhance capacities of clients and constituencies;

16. Apply knowledge of human behavior and the social environment, person-in- environment, and other multidisciplinary theoretical frameworks in interventions with clients and constituencies;

17. Use inter-professional collaboration as appropriate to achieve beneficial practice outcomes;

18. Negotiate, mediate, and advocate with and on behalf of diverse clients and constituencies; and facilitate effective transitions and endings that advance mutually agreed-on goals;

19. Select and use appropriate methods for evaluation of outcomes;

20. Apply knowledge of human behavior and the social environment, person-in- environment, and other multidisciplinary theoretical frameworks in the evaluation of outcomes; and

21. Critically analyze, monitor, and evaluate intervention and program processes and outcomes; and apply evaluation findings to improve practice effectiveness at the micro, mezzo, and macro levels (CSWE, 2015, pp. 7, 8, 9).

The CSWE policy program assessment includes two kinds of assessments: educational policy to evaluate student learning and outcomes, and an accreditation standards assessment.

a) Social Work Student Learning Outcomes

The nine CSWE competencies include the skills, knowledge, social values, and methods of assessments that can help social workers be effective in their practice. Social activities give social workers opportunities for training to develop their social skills, knowledge, and the practice of professional interventions according to social situations. Also, the evaluation process reflects on the explicit and implicit content in the social work curriculum as it relates to social workers' performance (CSWE, 2015).

\section{b) Accreditation Standards Assessment}

Each competency is subject to two assessment measures to show the proficiency in real practice and in simulation cases. The evaluation policy measures the degree to which each competency reflects how academic knowledge on social work practice is reflected in students' performance (CSWE, 2015). As stated by CSWE, "an explanation of how the program determines the percentage of students achieving the benchmark," and "copies of all assessment measures used to assess all identified competencies" (CSWE 2015, p. 18).

Each accredited social work programs in the United States must provide an annual summary of its evaluation of competency outcomes; each social work program has the option of issuing the results of its evaluation every two years. All social work education programs report on student learning and outcomes. The reports detail how well student performance meets the nine competencies and mastery of social work practice. Social work programs consider the students' scores and whether they meet the CSWE's criteria. Each program provides an evaluation summary that includes an explanation of its process for evaluating the results, and any changes made to the program (CSWE, 2015; Form AS4 (B).

Table 1: Baccalaureate social work program assessment of student learning outcomes (Form AS4 (B) (Assessmentof-Student-Learning-Outcomes, 2016).

\begin{tabular}{|l|c|c|}
\hline \multicolumn{1}{|c|}{ Competency } & Competency Benchmark & $\begin{array}{c}\text { Percentage of Students } \\
\text { Achieving Benchmark }\end{array}$ \\
\hline $\begin{array}{l}\text { Competency 1: Demonstrate } \\
\text { Ethical and Professional Behavior }\end{array}$ & $80 \%$ of all students will rate a "4" or higher & $90.3 \%$ \\
\hline $\begin{array}{l}\text { Competency 2: Engage Diversity } \\
\text { and Difference in Practice }\end{array}$ & $80 \%$ of all students will rate a "4" or higher & $95.2 \%$ \\
\hline $\begin{array}{l}\text { Competency 3: Advance Human } \\
\text { Rights and Social, Economic, and } \\
\text { Environmental Justice }\end{array}$ & $80 \%$ of all students will rate a "4" or higher & $89.2 \%$ \\
\hline $\begin{array}{l}\text { Competency 4: Engage in } \\
\text { Practice informed Research and } \\
\text { Research Informed Practice }\end{array}$ & $80 \%$ of all students will rate a "4" or higher & $86.2 \%$ \\
\hline $\begin{array}{l}\text { Competency 5: Engage in Policy } \\
\text { Practice }\end{array}$ & $80 \%$ of all students will rate a "4" or higher & $86.9 \%$ \\
\hline
\end{tabular}




\begin{tabular}{|l|l|c|}
\hline $\begin{array}{l}\text { Competency 6: Engage with } \\
\text { Individuals, Families, Groups, } \\
\text { Organizations, and Communities }\end{array}$ & $80 \%$ of all students will rate a "4" or higher & $90.6 \%$ \\
\hline $\begin{array}{l}\text { Competency 7: Assess } \\
\text { Individuals, Families, Groups, } \\
\text { Organizations, and Communities }\end{array}$ & $80 \%$ of all students will rate a "4" or higher & $91.9 \%$ \\
\hline $\begin{array}{l}\text { Competency 8: Intervene with } \\
\text { Individuals, Families, Groups, } \\
\text { Organizations, and Communities }\end{array}$ & $\begin{array}{l}80 \% \text { of all students will 80\% of all students } \\
\text { will rate a "4" or higher }\end{array}$ & $89.5 \%$ \\
\hline $\begin{array}{l}\text { Competency 9: Evaluate Practice } \\
\text { with Individuals, Families, Groups, } \\
\text { Organizations, and Communities }\end{array}$ & $80 \%$ of all students will rate a "4" or higher & $81.4 \%$ \\
\hline
\end{tabular}

Libyan social work educators can apply the CSWE assessment process in their social work education programs to develop students' performance and keep up with international social workers competencies.

In this respect, I give as an example, the basic requirement of undergraduate and graduate social work majors in Widener University's (WU) social work education curriculum. These requirements help students meet the CSWE competencies. The courses are as follows:

- Introduction to psychology and sociology

- Social work history and policy

- Social work and social welfare

- Human behaver and social environment, and culture diversity

- Interpersonal process,

- Social work field placement,

- Social work practice with individuals, families and groups, Social work with organizations, and

- Social work with communities. (WU, 2016, p. 122; WU, 2018, p. 8)

c) Recommendations and Vision for Establishing a Libyan Social Work Board

As a social worker, I am concerned about, and interested in, the social work profession, and I believe in the principles of the social work profession. Therefore, I encourage Libyan social work professionals to take advantage of modern model of social work education, and use the U.S. model of social work education to develop the Libyan social work education curriculum. In addition, I have several recommendations that might open the door for collaboration between Libya and the United States in the social work field:

- Re-examine the Libyan social work education curriculum and the methods of teaching students of the social service profession, where it is necessary, to graduate capable practitioners who can apply strategies that strengthen social work performance.
- Libyan social work educators should keep in mind that an outdated social work curriculum produce social workers who would not find a place in the contemporary workforce, and would not be able to ameliorate social issues, such as addiction, unemployment, poverty, violence, and lack of healthcare.

- Libyan social work educators should narrow the gap between advanced education that is technologybased with local education based on traditional education.

- Libyan social work professionals should follow the footsteps of developing countries that have applied advanced models of education to develop social work education. For example, the Malaysian models in Saudi Arabia, the Japanese and German models in Egyptian education, and the U.S. and Finnish models in United Arab Emirates education can all inform Libyan social work curriculum development.

- Libyan social work professionals should be open to applying advanced social work curriculum standards, such as the U.S. model, to develop the Libyan social work curriculum within the Libyan context. They should work to consolidate knowledge, skills, and work, in balance, to consolidate life skills and establish links between theoretical subjects and professional materials, to match the requirements of the local,national, and global labor market to meet the needs of disciplines and professions.

- Libyan social work professionals should be open to applying advanced social work curriculum standards, such as the U.S. model, to develop the Libyan social work curriculum within the Libyan context. They should link between theoretical subjects and professional materials to meet the needs of disciplines and professions, also, to match the requirements of the local labor market and the international market.

- Libyan social work educators should collaborate with U.S. social work educators, so they can take 
advantage of exchanging experiences and knowledge. In addition, Libyan social workers should attend U.S. social work conferences to access updated information about social work education and developing a curriculum.

- Libyan social work educators should take advantage of the CSWE's policies to establish a Libyan social work education board.

d) Vision for Establishing a Libyan Social Work Board

My general vision of establishing social work board in Libya is to create an independent social work education board within the high education ministry. This board would have an independent social work constitution, legislation, and career hierarchy in government institutions. It would also provide direct supervision to social and academic institutions, according to the social work profession, and would have its own budget and social work-related activities. Moreover, the board would have a right to work with social policy affairs and provide its vision and findings of social researches to help social policy convert social plans to social programs to facilitate providing social services. Furthermore, it would be independent entity, capable of developing social work divisions based on social work practice and would improve its social work education curriculum according to advanced social work education practice around the globe. This board would have own divisions to train social work students. Also, it would be free to make decisions on developing social work knowledge, skills, professional practice, and professional interventions according to social situations needs. The board should have own social researchers, research, policies based on that research, and a modern academic library. It should also have a dedicated website to publish scientific social research outcomes to make recommendations on dealing with contemporary social issues. Furthermore, the board would be able to track social workers' performance in the different social work fields and in educational institutions, and would be able to promote qualified social work professionals into positions in the Libyan council social work board, and represent Libya at international social work conferences and United Nations conferences. The Libyan board would be able to take advantage of different experiences from different cultures and attend advanced educational conferences that relate to development social work methods and upgrade the social workers performance. Moreover, one of the board's missions would be to train and employ social workers to work in educational and social institutions, based on different specializations and educational degree.

The board would have the authority to establish educational institutions that provide resources for social workers who wish to improve their social performance, professional career, academic and social knowledge, as well as their professional practice. Another of the board's missions would be to collaborate with advanced countries that have experience in integrating social workers within social institutions, which would help save both time and money, and help address Libyan social issues. By linking the social work board with Libyan government departments, and establishing social work departments in all government institutions, progress on solving social problems could be tracked to ensure that outcomes are consistent with the social work board's policies, as well as the Libyan government's policies.

\section{Conclusion}

This paper presented a proposal of applying the U.S. social work education experience to Libyan social work education. This proposal falls within the framework of developing social work curriculum that is both generalist and specialized. Since Libyan professionals are currently planning to develop the state's institutional missions to address the challenges of contemporary social issues and to develop social workers knowledge and skills to improve social work professional performance in social work education, I have suggested that Libyan social work professionals take advantages of the U.S. model in developing social work education. The reason for this recommendation is that the United States has successfully connected and integrated the social work profession with its social and educational institutions. In addition, the United States has an advanced program in social work education and works continuously on assessing and developing its social work education curriculum to ensure that social worker are competent and able to face global challenges.

I include in my proposal the nine U.S. competencies in social work education to encourage Libyan social work professionals to take advantage of integrating the U.S. model into the Libyan social work education curriculum, according to Libyan ideology. In addition to the proposal, this paper concluded with some recommendations that may help Libyan social work professionals develop the framework of social work education. I created a general vision for establishing an independent social work education board that can make its own decisions, has its own budget, and can advance the Libyan social work education missions free of the influence of traditional procedures.

\section{References Références Referencias}

1. Abdul Hamid, K. (n.d). alkhidmat alaijtimaeiat wahuquq al'iinsan [Social service and human rights]. Faculty of Cairo: Faculty of Social Work. https://www.mobt3ath.com/uplode/book/book17056.pdf

2. Abdulsalam. N. (2010) almithaq al'akhlaqiu lil'akhsayiyiyn alaijtimaeiiyn [Code of Ethics for social workers]. Nani Mohsen Ahmed Abdel Salam. 
https://kenanaonline.com/users/nannymuhsen1/pos ts/187752

3. Abou El Nasr, M. (2008). alaitijahat almueasirat fi mumarasat alkhidmat alaijtimaeiat alwiqayiya [Contemporary trends in the practice of preventive social service]. First edition. Nasr, Cairo: Nile Group

4. Abdu Al Aleem, M. (n.d). alkhidmat alaijtimaeiat fi almajal altaelimii [Social service in Mthe field of education]. http://www.siironline.org/alabwab/ mogtama\%20(23\%20)/340.htm

5. Ajlani, A. (2005). tuqim almaharat almihniat eind alakhsayyyn alaijtimaeiiyn dirasat mashiat fi mustashfayat alsihat alnafsiat bialmamlakat alearabiat alsaeudia [The professional skills of the social workers: Survey in a mental health hospital in Saudi Arabia]. Naif Arab University for Security Sciences, College of Graduate Studies, Department of Social Work. http://www.gulfkids.com/pdf/mahjtma.pdf

6. Al-Barithin, A. (2010). nahw tasawur lisiaghat dustur 'akhlaqiin earabiin lilkhidmat alaijtimaeia [Towards a vision for the drafting of an Arab moral constitution for social service]. majalat aleulum alaijtimaeia [Journal of Social Sciences]. http://swmsa.net/ forum/showthread. php? $\mathrm{p}=66531$

7. Albrithen, A. (2014). Social Work Education in Saudi Arabia: A Review. Social Development Issues, 2014, Vol. 36 Issue 1, p52-66, 15p, 10 Charts. Publisher: Follmer Group. https://0-content-ebscohostcom.libcat. widener.edu/ContentServer.asp? $\mathrm{T}=\mathrm{P} \& \mathrm{P}$ $=A N \& K=110537221 \& S=R \& D=$ sih \&EbscoContent $=\mathrm{dGJyMNHX8kSeqLE4yOvsOLCmr1CeqK5Ssqq4S}$ LeWxWXS\&ContentCustomer=dGJyMPGuskq0qb RRuePfgeyx $43 z x$

8. Brigham, T. (1982). Social work education patterns in five developing countries: Relevance of U.S. Microsystems Model. Journal of Education for Social Work, 18, (2), 68-75. http://www.jstor.org/stable/ 41350606

9. Dahir, M. (2013). mushkilat albahth alaijtimaeii walaintifadat alearabia [Problems of social research and Arab uprisings]. Al-Bayan Newspaper. https:// www.albayan.ae/opinions/articles/2013-11-20-1. 2003160

10. Council on Social Work Education. (2015). 2015 Educational policy and accreditation standards for baccalaureate and master's social work programs. https://www.cswe.org/getattachment/Accreditation/ Accreditation-Process/2015-EPAS/2015EPAS Web FINAL.pdf.aspx

$\begin{array}{llll}\text { 11. Form AS4 } & \text { (B). (2016). Retrieved from }\end{array}$ https://socialwork.umbc.edu/files/2016/08/2015-16Assessment-of-Student-Learning-Outcomes.pdf

12. House, L. (2018). Editing notes SW 863 Development as a Scholar-Practitioner. Widener University, Social work education Delivered summer Semester/2018.
13. Libyan Cloud News Agency. (2018).[ aintilaq almultaqaa al'akadimii lilkhidmat alaijtimaeiat baljamieat alliybiat bitarabulus]. The launching of the academic forum for social service in the Libyan universities in Tripoli. http://libyan-cna.net/libyan cloud-news/27636

14. Pawar, M. (2014). Social work practice with local communities in developing countries: Imperatives for political engagement. Sate Open. 1-11. doi:10. 1177/2158244014538640. http://journals.sagepub. com/doi/pdf/10.1177/2158244014538640

15. CSUS MASTER OF SOCIAL WORK PROGRAM. (2017). Assessment of student learning outcomes CSUS Master of Social Work program. https://www. csus.edu/hhs/sw/cswe-form-as4-m.pdf

16. Salih, A. (2000). Role of the task force in social work and stimulate student participation in the political process. Cairo University, Faculty of Social Work. http://fayoum.edu.eg/SocialWork/FieldsofSocialWor k/pdf/DrAhmed17.pdf

17. Serogi, T. (2012, December, 8). alrbye aleurbaa watahadiyat alkhidmat alaijtimaeia ruyat fa mustaqbal alkhidmat alaijtimaeiat alearabia [Arab Spring and the challenges of social service vision in the future of Arab social service]. http://talaa telsrogiblogspotcom.blogspot.com/2011/12/blogpost_18.html

18. Soliman, H., \& Abd Elmegied, H. (2010). The challenges of modernization of social work education in developing countries: The case of Egypt. International Social Work. 53(1) 101-114. DOI: 10.1177/0020872809348951

19. Shall, M. (2013). altadakhul almuhnaa fa alkhidmat alaijtimaeia [Professional intervention in social service]. Graduate Studies, Faculty of Social Work, Helwan University. http://kenanaonline.com/users/ malshaarawy/posts/492725

20. United Nations Educational, Scientific and Cultural Organization. (1999). Improving the effectiveness of curriculum development and reform in Africa: A handbook for curriculum planners. http://unesdoc. unesco.org/images/0012/001202/120251Eo.pdf

21. Widener University. (2016). Center for Social Work Education 2016 Graduate Catalog. http://www. widener.edu/academics/catalogs/_docs/current/SW 16Cat.pdf\#page $=8$

22. Widener University. (2017). Widener University 2017-2018 Undergraduate Catalog. http://www. widener.edu/academics/catalogs/_docs/current/UG 17Cat.pdf \#page $=122$ 